\title{
Prevalence of Malnutrition in Children with Congenital Heart Disease
}

\author{
Avisa Tabib ${ }^{1}$, Maryam Aryafar ${ }^{2,{ }^{*}}$ and Behshid Ghadrdoost ${ }^{2}$ \\ ${ }^{1}$ Heart Valve Disease Research Center, Rajaei Cardiovascular Medical and Research Center, Iran University of Medical Sciences, Tehran, Iran \\ ${ }^{2}$ Rajaei Cardiovascular Medical and Research Center, Iran University of Medical Sciences, Tehran, Iran \\ "Corresponding author: Rajaei Cardiovascular Medical and Research Center, Iran University of Medical Sciences, Tehran, Iran. Email: aryafarmaryam@yahoo.com
}

Received 2018 September 15; Revised 2019 July 22; Accepted 2019 August 03.

\begin{abstract}
Background: Congenital heart defect (CHD) is the most common congenital anomaly in infants and is known to be a leading cause of malnutrition.

Objectives: This study aimed to provide insights into the prevalence of malnutrition in children with CHD in Iran.

Methods: The study enrolled 515 under-five children with CHD. The diagnosis was based on the definitive result of cardiac catheterization report. They were divided into the subgroups of cyanotic with pulmonary hypertension (PH), acyanotic with $\mathrm{PH}$, cyanotic without $\mathrm{PH}$, and acyanotic without $\mathrm{PH}$ according to their diagnosis. The degree of growth failure and the severity of malnutrition were evaluated based on the WHO standards (z-score criteria) in three categories as mild (-1.1 to -2.0 SD), moderate (-2.1 to -3.0 SD), and severe $(\leq 3 \mathrm{SD})$.

Results: Among the studied groups, the most prevalent CHDs were ventricular septal defect(VSD; 42.9\%) and tetralogy of Fallot (TOF; 17.3\%). Severe malnutrition was significantly more prevalent in cyanotic patients with and without $\mathrm{PH}(\mathrm{n}=23 ; 63.9 \%$ and $n=89 ; 51.1 \%$, respectively). Normal nutritional status was significantly more in acyanotic patients without $\mathrm{PH}(\mathrm{P}<0.001)$. Overall, malnutrition in this study was mild in $16.3 \%$, moderate in $24.1 \%$, and severe in $39.8 \%$ of cases.

Conclusions: The study showed that the prevalence of malnutrition in children with CHD aged under 5 years was noticeably high at this center in Iran. The administration of nutritional requirements such as low-volume and high-calorie diets should be considered for these vulnerable children.
\end{abstract}

Keywords: Malnutrition, Congenital Heart Disease, Pulmonary Hypertension, Cyanotic, Acyanotic

\section{Background}

Congenital heart defect (CHD), also known as congenital heart disease, occurs due to a defect in the formation of the heart structure or its vessels during the embryonic period. Such diseases can range from simple and mild cardiac diseases, which cause no serious problems, to complex and severe cardiac diseases, which may lead to the emergence of severe complications in infants (1). The prevalence of CHD among infants has shown to be different in various studies ranging from 6 to 10 cases per 1000 births (2).

Regarding the clinical manifestations, CHDs are divided into two groups, namely cyanotic and acyanotic heart defects. The most common cyanotic defects include tetralogy of Fallot (TOF), pulmonary atresia (PA), transposition of great arteries (TGA), and tricuspid atresia (TA). Also, the common acyanotic defects include patent ductus arteriosus (PDA), ventricular septal defect (VSD), atrial septal defect (ASD), aortic stenosis (AS), coarctation of the aorta (COA), and pulmonary stenosis (PS) (3).

Malnutrition is of high prevalence among CHD infants and plays an important role in mortality, hospital infections, and increased length of stay (LOS) of such infants. Regarding the limited protein and fat reserves, high energy expenditure, and increased energy requirement for further growth, infants are more prone to malnutrition than adults. The newborn infants with $\mathrm{CHD}$, particularly those with pulmonary hypertension ( $\mathrm{PH})$, will commonly have poor postnatal weight gain despite good birth weight (2).

The degree of malnutrition may be associated with the characteristics of CHD, including the presence of cyanosis and $\mathrm{PH}$. Infants with cyanosis are prone to retardation in both weight and length. Infants with acyanotic lesions have difficulty in gaining weight. Thus, cyanotic defects and $\mathrm{PH}$ are very high-risk conditions for these infants (1).

The incidence of malnutrition in infants with cardiovascular diseases (CVDs) depends on several factors, including:

1) Insufficient nutrient intake caused by anorexia due to side effects of medications, fatigue during feeding, 
swallowing problems (dysphagia) such as uncoordinated breast sucking, neurological dysfunction, laryngeal dysfunction, nausea and reflux, early satiety due to the reduced gastric volume caused by hepatomegaly or ascites, tachypnea, observing fluid intake restrictions, NPO courses in hospitals for performing therapeutic processes, and recurrent respiratory infections (4-6);

2) Increased energy requirement caused by severe metabolic stress responses in CHF, postoperative metabolic stress, relative increase in fat-free mass to fat mass ratio in malnourished patients, tachypnea, tachycardia, cardiac hypertrophy, polycythemia for chronic hypoxia compensation, increased activity of sympathetic system, infection, fever, and sepsis (4-6);

3) Malabsorption of nutrients due to nausea, decreased splanchnic blood flow, poor gastric emptying, intestinal motility changes, intestinal wall edema (due to right-sided heart failure) resulting in malabsorption, considerable excretion of nutrients such as protein-losing enteropathy and steatorrhea, excretion of trace elements such as calcium and potassium, intestinal mucosal atrophy causing malabsorption, and lack of insulin-like growth factor (IGF1) (4-6).

\section{Objectives}

Thus far, no accurate statistics have been presented on the prevalence of malnutrition among Iranian infants with congenital cardiovascular diseases. Thus, the present study aimed to estimate the prevalence of malnutrition among under five-year-old infants with CHD referring to Rajaei Cardiovascular Medical and Research Center. The study paves the way for applying appropriate nutritional strategies to prevent malnutrition progress during the hospital stay and thereby, take some steps toward resolving the problem.

\section{Methods}

The present cross-sectional study was conducted on 515 under-five infants with CHD referring to Rajaei Cardiovascular Medical and Research Center from July 2016 to January 2017. The infants were admitted for the first time to the children's wards. The data including height $(\mathrm{cm})$, weight $(\mathrm{kg})$, and age (months) of the infants were recorded by a trained nurse immediately on admission. The infants' weight was measured by a Seca 334 portable digital baby scale (with the accuracy of less than $5 \mathrm{~g}$ ) and a Seca 786 mechanical column scale (with the accuracy of $0.3 \mathrm{~kg}$ ) and their height was determined using Seca 217 and Seca 207 stadiometers with the accuracy of $1 \mathrm{~mm}$.
Furthermore, the diagnosis of the disease was based on the patients' echocardiography reports. The PH status of the studied infants was determined using the given Cath reports. The mean pulmonary arterial pressure of above 25 $\mathrm{mmHg}$ was considered as the indication of PH. In terms of age, the infants fell into the age group of 0 - 60 months.

We excluded infants with genetic disorders such as Down syndrome or other anomalies that might have affected feeding abilities and ergo worsen malnutrition such as the cleft palate and neuromuscular problems. The studied patients were divided, based on the type of disease, into four groups including (1) acyanotic with PH, (2) acyanotic without $\mathrm{PH}$, (3) cyanotic with $\mathrm{PH}$, and (4) cyanotic without $\mathrm{PH}$.

The degree of the infants' malnutrition severity was evaluated based on their weight for age, height for age, and weight for height in accordance with the WHO standards, which led to the classification of malnutrition severity in three groups, namely light (mild) (-1.1 to -2.0 SD), moderate $(-2.1$ to $-3.0 \mathrm{SD})$ and severe $(\leq 3 \mathrm{SD})$.

\subsection{Statistical Analysis}

Statistical analysis was performed using SPSS 22 for Windows (SPSS Inc., Chicago, Illinois). Data were expressed as means \pm standard deviation numerical variables and count (\%) for categorical variables. One-sample Kolmogorov-Smirnov test was used for evaluating the distribution of data. Mann-Whitney U test, Wilcoxon test, and chi-square test were employed to test the relationship between the variables and groups. A multivariable logistic regression model was developed based on variables with significant results $(\mathrm{P}<0.05)$ from univariable analysis to predict severe malnutrition in patients with CHD. A P value of $<0.05$ was considered statistically significant.

\section{Results}

In total, 515 children with CHD were included in the study. The mean age of the patients was $19.9 \pm 16.8$ months and 239 patients $(46.4 \%)$ were male. The frequency of cardiovascular defects in patients is demonstrated in Figure 1 .

The highest prevalence rate of CHDs in this study was related to VSD (42.9\%), followed by TOF (17.3\%). Regarding the type of disease (i.e. cyanotic or acyanotic) and the presence/absence of $\mathrm{PH}$, the studied infants were divided into four groups: cyanotic infants with $\mathrm{PH}(\mathrm{n}=36,7 \%)$, acyanotic infants with $\mathrm{PH}(\mathrm{n}=157,30.5 \%)$, cyanotic infants without $\mathrm{PH}$ $(\mathrm{n}=174,33.8 \%)$, and acyanotic infants without $\mathrm{PH}(\mathrm{n}=148$, 28.7\%).

The demographic characteristics and anthropometric measurements in the groups are shown in Table 1. There 


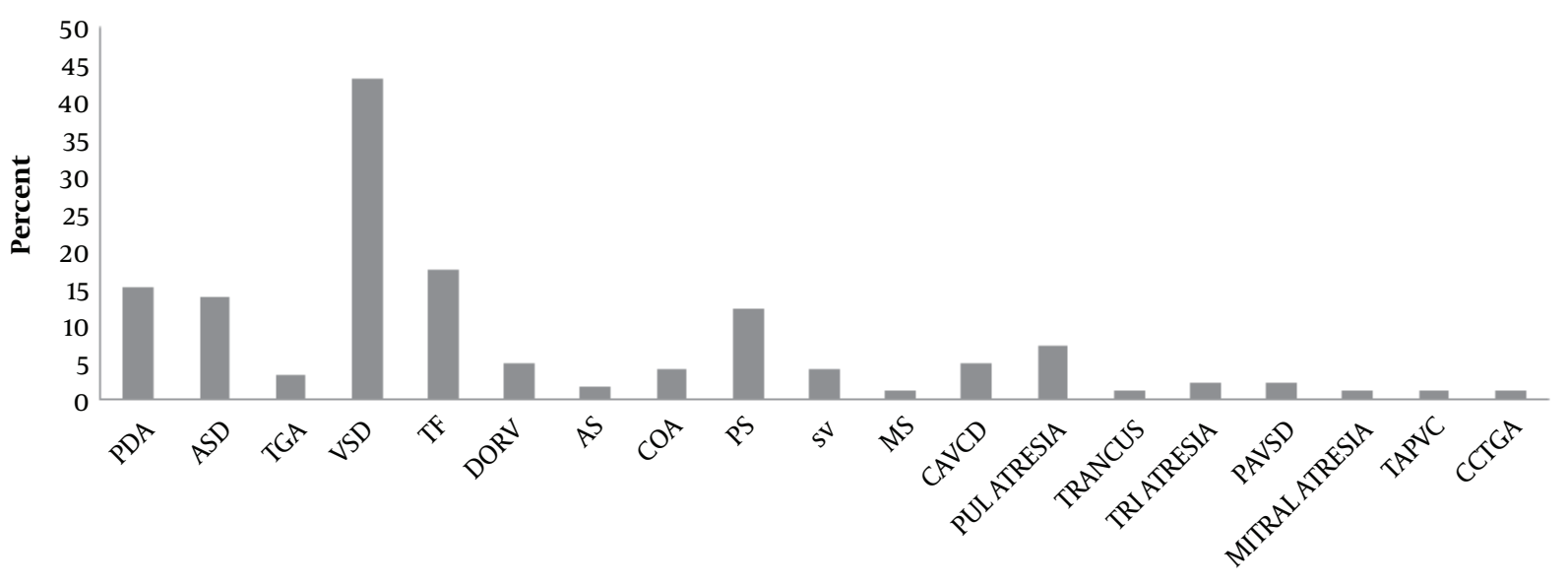

Type of Congenital Anomaly

Figure 1. Frequency of cardiovascular defects in patients

were significant differences between the groups in terms of age $(\mathrm{P}=0.04)$, weight $(\mathrm{P}=0.01)$, and height $(\mathrm{P}=0.01)$. Cyanotic patients with $\mathrm{PH}$ had significantly lower age, weight, and height.

The type and the severity of malnutrition were determined in infants through comparing their height and weight with standard tables; then, the relationship between malnutrition and heart diseases was evaluated. The nutritional status of the patients is demonstrated in Table 2. Among the studied infants, 102 infants (19.8\%) had the normal status of nutrition, whereas 84 infants (16.3\%) were diagnosed with mild malnutrition, 124 (24.1\%) with moderate malnutrition, and 205 (39.8\%) with severe malnutrition.

The association between the severity of malnutrition and the cardiac diagnostic groups is given in Table 3. Severe malnutrition was significantly more prevalent in cyanotic patients with and without $\mathrm{PH}(\mathrm{n}=23 ; 63.9 \%$ and $\mathrm{n}=89$; $51.1 \%$, respectively). Normal nutritional status was significantly more in acyanotic patients without $\mathrm{PH}(\mathrm{P}<0.001)$.

After adjusting for the type of cardiac disease and the age of infants in multivariate analysis, severe malnutrition was significantly associated with cardiac diagnosis (cyanosis OR (95\% CI): 4.571 (2.914 - 7.170), P $<0.001$ and $\mathrm{PH}$ OR (95\% CI):3.724 (2.315-5.990), P < 0.001; Table 4). Weight was not included in the multivariate model because it is the main factor in malnutrition definition (Table 4).

\section{Discussion}

Malnutrition is one of the main problems among infants with CHD. Mehrizi and Drash reported the malnutri- tion prevalence of $55 \%$ among CHD infants. In addition, the prevalence of malnutrition was reported as $65 \%$ among infants with CHD in Turkey (7).

The causes of malnutrition in children with CHD include insufficient energy intake, nausea-induced malabsorption, decreased splanchnic blood flow, delayed gastric emptying, intestinal edema, and increased nutrient excretion in conditions such as fatty diarrhea, protein-losing enteropathy, and increased energy requirement. Therefore, the lack of energy intake is the most important identified cause of malnutrition and growth retardation among these infants. Anorexia is also common among these infants and it is another factor that reduces their food intake and worsens their status. In addition, chronic hypoxia can lead to anorexia and nutritional problems in cardiac patients, one of the complications of which is malabsorption. In children with CHD, the heart and lungs get overworked, which can result in the increased energy requirement. Typically, these children need 50\% more calorie intake than their healthy peers. Consequently, these factors altogether would lead to the worsening of their nutritional conditions and the incidence of malnutrition in these children (7).

To date, numerous studies have addressed the effect of CHDs on children's growth. In this regard, Linde et al. showed the delayed height and weight growth among cyanotic infants compared to acyanotic ones. Nevertheless, they disregarded the effect of pulmonary hypertension on malnutrition (8). Salzer et al. reported that infants with a left-to-right shunt were more prone to weight loss, and were also thinner than those with cyanotic diseases (9). 


\begin{tabular}{|c|c|c|c|c|c|}
\hline & $\begin{array}{l}\text { Cyanotic Infants with } \\
\text { PH }(N=36)\end{array}$ & $\begin{array}{l}\text { Acyanotic Infants } \\
\text { with } \mathrm{PH}(\mathrm{N}=157)\end{array}$ & $\begin{array}{l}\text { Cyanotic Infants Without PH } \\
\qquad(N=174)\end{array}$ & $\begin{array}{l}\text { Acyanotic Infants Without PH } \\
\qquad(\mathrm{N}=148)\end{array}$ & P Value \\
\hline Age & $9.25 \pm 13.3$ & $14.33 \pm 14.7$ & $21.12 \pm 15.3$ & $27.29 \pm 17.9$ & 0.04 \\
\hline Sex & & & & & 0.07 \\
\hline Male & $11(30.6)$ & $85(54.1)$ & $76(43.7)$ & $67(45.3)$ & \\
\hline Female & $25(69.4)$ & $72(45.9)$ & $98(56.3)$ & $81(54.7)$ & \\
\hline Weight, kg & $5.90 \pm 3.1$ & $7.15 \pm 3.08$ & $9.79 \pm 3.45$ & $10.78 \pm 4.04$ & 0.01 \\
\hline Height, cm & $65.5 \pm 12.9$ & $70.7 \pm 13.7$ & $79.4 \pm 14.5$ & $85.6 \pm 14.7$ & 0.01 \\
\hline
\end{tabular}

Table 2. Nutritional Status and Patterns of Malnutrition in Patients

\begin{tabular}{lc}
\hline Nutritional Status & No. (\%) \\
\hline Normal & $102(19.8)$ \\
Mild malnutrition & $84(16.3)$ \\
Moderate malnutrition & $124(24.1)$ \\
Severe malnutrition & $205(39.8)$ \\
\hline
\end{tabular}

The present study was conducted on 515 infants with CHD aged less than 5 years ( 0 - 60 months), including 239 males (46.4\%) and 276 females (53.5\%), who were admitted to Shahid Rajaei Cardiovascular Medical and Research Center. The highest prevalence rate of CHDs in this study was related to VSD (42.9\%), followed by TOF (17.3\%). Regarding the type of disease (i.e. cyanotic or acyanotic) and the presence/absence of $\mathrm{PH}$, the studied infants were divided into four groups: cyanotic with $\mathrm{PH}(\mathrm{n}=36,7 \%)$, acyanotic with $\mathrm{PH}(\mathrm{n}=157,30.5 \%)$, cyanotic without $\mathrm{PH}(\mathrm{n}=174,33.8 \%)$, and acyanotic without $\mathrm{PH}(\mathrm{n}=148,28.7 \%)$. The type and severity of malnutrition in these infants were determined by comparing their height and weight with standard tables to examine the relationship between malnutrition and heart diseases.

The results obtained in the present study were comparable with those of other similar studies in this regard. Cyanotic infants with PH had significantly lower age, weight, and height. The nutritional status of these infants is shown in Table 2. Among the studied infants, 102 infants $(19.8 \%)$ had the normal status of nutrition, whereas 84 (16.3\%) were diagnosed with mild malnutrition, 124 (24.1\%) with moderate malnutrition, and 205 (39.8\%) with severe malnutrition. The prevalence of malnutrition was higher among cyanotic infants with $\mathrm{PH}(\mathrm{n}=23 ; 63.9 \%)$ and cyanotic infants without $\mathrm{pH}(\mathrm{n}=89 ; 51.1 \%)$ than in the two other groups. Also, acyanotic infants without $\mathrm{PH}$ were more frequently in normal nutritional status $(\mathrm{P}<0.001)$.

In a similar study conducted by Varan et al., 89 infants with CHD aged 1- 45 months were divided into four groups: (1) cyanotic with $\mathrm{pH},(2)$ cyanotic without $\mathrm{pH}$, (3) acyanotic with $\mathrm{PH}$, and (4) acyanotic without $\mathrm{PH}$. The infants were investigated for malnutrition factors, which showed that cyanotic infants with PH were more affected and suffered from malnutrition. Besides, in this study, mild malnutrition was more prevalent in the group of acyanotic infants with $\mathrm{pH}$ and the majority of these infants (88\%) had either a good nutritional status or mild malnutrition. The moderate and severe levels of malnutrition were more prevalent in the group of cyanotic infants with $\mathrm{PH}$, but short height was more common than low weight in the group of cyanotic infants without $\mathrm{PH}$ (10).

According to Villasis-Keever et al. study on 244 children with CHD aged below 17 years, the most common congenital defects were identified in acyanotic children with PH (62.7\%), followed by cyanotic CHD without PH (15.6\%), acyanotic CHD without $\mathrm{PH}$ (11.5\%), and cyanotic CHD with $\mathrm{PH}(10.2 \%)$. The overall prevalence rates of malnutrition were $40.9 \%, 24.6 \%$, and $31.1 \%$ in terms of weight for age, height for age, and weight for age, respectively. Also, in this study, cyanotic children with PH were in the worst nutritional status (11).

As indicated by Leite et al. study on 30 infants with the left-to-right shunt (16 with $\mathrm{PH}$ and 14 without $\mathrm{pH}$ ), malnutrition was more prevalent (83.3\%) among infants with $\mathrm{PH}$ $(\mathrm{P}=0.01)$ so that this group was more prone to wasting than the group without PH. Finally, PH was shown to be an underlying factor that provides the ground for nutritional problems (12).

In this regard, Blasquez et al. conducted a study on 125 infants with CHD aged below 6 months, in which infants were divided into four groups, including infants who had neither cyanosis nor $\mathrm{PH}(\mathrm{n}=41)$, infants with cyanosis ( $\mathrm{n}$ $=52)$, infants with $\mathrm{PH}(\mathrm{n}=16)$, and cyanotic infants with $\mathrm{PH}(\mathrm{n}=10)$. Malnutrition in these infants was evaluated by measuring their height and weight, the results of which showed that the prevalence of moderate and severe malnutrition was the highest (100\%) in the fourth group (i.e. cyanotic infants with $\mathrm{PH}$ ). Furthermore, in this study, the overall prevalence of malnutrition among infants with CHD was estimated at about $15 \%$, which was lower than that in 


\begin{tabular}{lcccc}
\hline Table 3. Nutritional Status in Four Groups & & & \\
\hline Severe Malnutrition & $\begin{array}{c}\text { Cyanotic Infants with } \\
\mathbf{P H}(\mathbf{N}=\mathbf{3 6})\end{array}$ & $\begin{array}{c}\text { Acyanotic Infants with } \\
\mathbf{P H}(\mathbf{N}=\mathbf{1 5 7})\end{array}$ & $\begin{array}{c}\text { Cyanotic Infants } \\
\text { Without PH (N=174) }\end{array}$ & $\begin{array}{c}\text { Acyanotic Infants } \\
\text { Without PH (N=148) }\end{array}$ \\
\hline Yes & $23(63.9)$ & $73(46.5)$ & $89(51.1)$ & $25(16.9)$ \\
No & $13(36.1)$ & $84(53.5)$ & $123(83.1)$ & $305(59.2)$ \\
\hline
\end{tabular}

\begin{tabular}{|c|c|c|c|}
\hline & B & OR $(95 \% \mathrm{CI})$ & P Value \\
\hline Cyanosis & 1.520 & $4.571(2.914-7.170)$ & $<0.001$ \\
\hline PH & 1.31 & $3.724(2.315-5.990)$ & $<0.001$ \\
\hline Age & -0.001 & $0.999(0.987-1.011)$ & 0.91 \\
\hline
\end{tabular}

other similar studies (13).

According to the findings of this study and other studies in this regard, the presence of pulmonary hypertension is considered as one of the main causes of malnutrition among children $(14,15)$.

\subsection{Research Limitations}

Our study ignored many other factors, such as economic and cultural status of families, food and calorie intake, and the real needs of CHD children, which might have contributed to the incidence of malnutrition. Another limitation of the present work was the lack of reporting the biochemical and blood factors such as $\mathrm{Hb}$, serum albumin, total protein, etc.

\subsection{Conclusions}

The prevalence of malnutrition in children with CHD aged under five years was noticeably high at this center in Iran. The early treatment of these patients and the elimination of cyanosis followed by HP reduction are vital for resolving and improving malnutrition. However, with regard to the relatively high prevalence of malnutrition among children with CHD, especially cyanotic children with $\mathrm{PH}$, it is essential to take appropriate measures for improving the nutritional status of this group of patients since malnutrition can lead to complications such as the increased risk of infection, prolonged hospital stay, and even death.

\section{Acknowledgments}

We would like to thank all pediatric cardiology staff at Rajaei Cardiovascular Research Center who assisted in this study.

\section{Footnotes}

Authors' Contribution: Study concept and design: Maryam Aryafar; technical and material support and project conduct: Avisa Tabib; revising the manuscript: Avisa Tabib, Behshid Ghadrdoost, and Maryam Aryafar; collecting the data and reviewing the literature: Maryam Aryafar and Avisa Tabib; data analysis and drafting of the manuscript: Behshid Ghadrdoost.

Conflict of Interests: There was no conflict of interests in this study.

Ethical Approval: This study was approved by a local research ethics committee.

Financial Disclosure: There was no financial disclosure in this study.

Funding/Support: There was no funding for this study.

Patient Consent: Informed consent was taken from each participant.

\section{References}

1. Wheat JC. Nutritional management of children with congenital heart disease. Nutr Bytes. 2002;8(2).

2. Hagau N, Culcitchi C. Nutritional support in children with congenital heart disease. Nutr Ther Metab. 2010;28(4):172-84.

3. Owens JL, Musa N. Nutrition support after neonatal cardiac surgery. Nutr Clin Pract. 2009;24(2):242-9. doi: 10.1177/0884533609332086. [PubMed: 19321898].

4. Okoromah CA, Ekure EN, Lesi FE, Okunowo WO, Tijani BO, Okeiyi JC. Prevalence, profile and predictors of malnutrition in children with congenital heart defects: A case-control observational study. Arch Dis Child. 2011;96(4):354-60. doi: 10.1136/adc.2009.176644. [PubMed: 21266339]. [PubMed Central: PMC3056291].

5. De Staebel O. Malnutrition in Belgian children with congenital heart disease on admission to hospital. J Clin Nurs. 2000;9(5):784-91. doi: 10.1046/j.1365-2702.2000.00409.x.

6. Chen CW, Li CY, Wang JK. Growth and development of children with congenital heart disease. J Adv Nurs. 2004;47(3):260-9. doi: 10.1111/j.1365-2648.2004.03090.x. [PubMed: 15238120].

7. Tokel K, Azak E, Ayabakan C, Varan B, Aslamaci SA, Mercan S. Somatic growth after corrective surgery for congenital heart disease. TurkJPediatr. 2010;52(1):58-67. [PubMed: 20402068].

8. Linde LM, Dunn OJ, Schireson R, Rasof B. Growth in children with congenital heart disease. J Paediatr. 1967;70(3, Part 1):413-9. doi: 10.1016/S0022-3476(67)80139-2.

9. Salzer HR, Haschke F, Wimmer M, Heil M, Schilling R. Growth and nutritional intake of infants with congenital heart disease. Pediatr Cardiol.1989;10(1):17-23. doi: 10.1007/BF02328630. [PubMed: 2495525]. 
10. Varan B, Tokel K, Yilmaz G. Malnutrition and growth failure in cyanotic and acyanotic congenital heart disease with and without pulmonary hypertension. Arch Dis Child. 1999;81(1):49-52. doi: 10.1136/adc.81.1.49. [PubMed: 10373135]. [PubMed Central: PMC1717989].

11. Villasis-Keever MA, Aquiles Pineda-Cruz R, Halley-Castillo E, AlvaEspinosa C. [Frequency and risk factors associated with mal nutrition in children with congenital cardiopathy]. Salud Publica Mex. 2001;43(4):313-23. Spanish. [PubMed: 11547592].

12. Leite HP, de Camargo Carvalho AC, Fisberg M. Nutritional status of children with congenital heart disease and left -to -right shunt. The importance of presence of pulmonary hypertension. Arg Bras Cardiol.
1995;65(5):403-7.

13. Blasquez A, Clouzeau H, Fayon M, Mouton JB, Thambo JB, Enaud $\mathrm{R}$, et al. Evaluation of nutritional status and support in children with congenital heart disease. Eur J Clin Nutr. 2016;70(4):528-31. doi 10.1038/ejcn.2015.209. [PubMed: 26695725].

14. Costello CL, Gellatly M, Daniel J, Justo RN, Weir K. Growth Restriction in infants and young children with congenital heart disease. Congenit Heart Dis. 2015;10(5):447-56. doi: 10.1111/chd.12231. [PubMed: 25385245]

15. Toole BJ, Toole LE, Kyle UG, Cabrera AG, Orellana RA, Coss-Bu JA. Perioperative nutritional support and malnutrition in infants and children with congenital heart disease. Congenit Heart Dis. 2014;9(1):15-25. doi: 10.1111/chd.12064. [PubMed: 23602045]. 